\title{
An Inverse Relationship between Serum Vitamin C and Blood Pressure in a Japanese Community
}

\author{
Norimitsu Sakai, ${ }^{1, *}$ Tetsuji Yokoyama, ${ }^{1}$ Chigusa Date, ${ }^{2}$ \\ Nobuo Yoshirke ${ }^{3}$ and Yasuhiro MATSUMURA ${ }^{3}$ \\ ${ }^{1}$ Department of Epidemiology, Medical Research Institute, \\ Tokyo Medical and Dental University, Chiyoda-ku, Tokyo 101-0062, Japan \\ ${ }^{2}$ Department of Public Health, Osaka City University Medical School, \\ Osaka 545-0051, Japan \\ ${ }^{3}$ Division of Adult Health Science, National Institute of Health and Nutrition, \\ Tokyo 162-8636, Japan
}

(Received June 17, 1998)

Summary To examine the relationship between serum vitamin C concentration and blood pressure level, a cross-sectional study was conducted. The subjects were 919 men and 1,266 women aged 40 years and over in a Japanese provincial city, Shibata, Niigata Prefecture. The mean and standard deviation of systolic blood pressure (SBP) were $134.0 \pm 20.0 \mathrm{mmHg}$ for men and $128.3 \pm 20.8 \mathrm{mmHg}$ for women, and those of diastolic blood pressure (DBP) were $81.0 \pm 11.7 \mathrm{mmHg}$ and $75.8 \pm 11.4 \mathrm{mmHg}$, respectively. The mean and standard deviation of serum vitamin $\mathrm{C}$ were $42.5 \pm 18.6 \mu \mathrm{mol} / \mathrm{L}$ for men and $56.8 \pm 16.5 \mu \mathrm{mol} / \mathrm{L}$ for women. SBP and DBP were both inversely correlated with serum vitamin $\mathrm{C}$ concentration. The means of SBP or DBP were calculated for quartiles of serum vitamin $C$, and the significant inverse relationship was observed in any sex and age group. The inverse association persisted after adjustment for possible confounders: body mass index, serum total cholesterol, alcohol consumption, smoking, physical activity, antihypertensive medication, and dietary intake of salt, calcium, and potassium. Serum vitamin $C$ appeared to be inversely related with both SBP and DBP in this Japanese population, although further intervention and experimental studies were required to establish the cause-effect relationship.

Key Words vitamin C, systolic blood pressure, diastolic blood pressure, confounders, linear regression model

*To whom correspondence should be addressed. E-mail: baba.epi@mri.tmd.ac.jp 
Several epidemiological studies suggested that vitamin C (ascorbic acid) status was inversely associated with blood pressure $(1-17)$ and that a high intake of vitamin $\mathrm{C}$ was related to a reduced incidence of stroke (18) and myocardial infarction (19). In Japan, however, few reports have been made on the relationship between vitamin $\mathrm{C}$ status and hypertension or cardiovascular disease (3).

The putative protective effect of vitamin $\mathrm{C}$ on hypertension could reflect an artifact of other dietary factor(s), which are inseparable from vitamin $\mathrm{C}$ intake as far as humans are concerned. Therefore before we make a final conclusion about blood pressure-vitamin $\mathrm{C}$ relationship, adequate statistical adjustment should be made at least for important known confounding variables. Attempts were previously made to adjust confounding by other factors, but their adequacy has been questioned. Some investigators recommended further studies that could adequately address the issue of complex confounding $(11,20)$.

In the present study, we examined the cross-sectional association of serum vitamin $\mathrm{C}$ with blood pressure in a Japanese rural population, considering several confounding variables that included other dietary factors.

\section{METHODS}

Subjects. A longitudinal study of cardiovascular disease has been conducted in the Akadani-Ijimino district (hereinafter referred to as the A-I district), Shibata City, Niigata Prefecture, Japan, for 20 years. Using all residents aged 40 years and over, 1,182 men and 1,469 women as the eligible population, a baseline examination was carried out in July 1977. The details of the method were described in previous reports (21). On the basis of data at the baseline examination, we analyzed a relationship between serum vitamin $\mathrm{C}$ and blood pressure.

Blood pressure measurement. Staff nurses, who were trained by means of an audiovisual system, measured casual blood pressure at rest by using a Riva-Rocci sphygmomanometer as prescribed by procedures of the World Health Organization (22). Two readings separated by about $2 \mathrm{~min}$ were taken after the subject had a 5 -min rest in a sitting position. The average of these two readings was used for the present analysis. If the first two readings differed by $6 \mathrm{mmHg}$ or more, an additional reading was taken and the closest pair was used to obtain the average.

Serum vitamin $C$ measurement. The serum concentration of vitamin $\mathrm{C}$ was determined on nonfasting venous blood by the 2,3-dinitrophenylhydrazine method with calorimetric analysis (23). Immediately after separating serum by centrifugation, the sample was deproteinized, and the supernatant of serum was stored at $-20^{\circ} \mathrm{C}$ on the basis of our stability study (24). The measurements of all samples were completed within $10 \mathrm{~d}$.

Although the method was then known to be not only simple, but also accurate and precise, the precision was reconfirmed by measuring the serum level of vitamin C 15 times for a randomly selected sample in each run. The coefficients of variation fell within a range of $5.0 \%$ for any run $(24)$. 
Possible confounding variables. Among factors that appeared to relate to blood pressure, we employed body mass index (BMI), serum total cholesterol, alcohol consumption, smoking, physical activity, antihypertensive medication, and dietary intake of salt, calcium, and potassium in the present study.

After height and weight were measured, BMI was calculated as (weight in kilograms)/(height in meters) ${ }^{2}$. Serum total cholesterol was measured with Auto Analyzer AA-II (Technicon, NY). Standardization was achieved by participation in the Lipid Standardization Program of the Centers for Disease Control and Prevention, U.S.A.

A standardized questionnaire was used to assess lifestyle factors by trained interviewers or dietitians. Alcohol consumption was categorized as nondrinkers, ex-drinkers, and drinkers. The current drinkers were asked how many drinks they took daily ( 1 drink $=12 \mathrm{~g}$ of ethanol). As for smoking, the subjects were classified into three groups: nonsmokers, ex-smokers, and smokers. The current smokers were asked how many cigarettes per day they smoked. In another questionnaire that included information on the energy-consuming tasks and the time spent in doing them, the degree or intensity of average physical activity was assessed by using an index that was calculated by the method of the Japanese Ministry of Health and Welfare (25): When the index was 0.35 for an individual, his/her physical activity was considered to be light; 0.50 , moderate; 0.75 , slightly heavy; and 1.00 , heavy. The persons who had antihypertensive medication were identified; none was receiving vitamin supplement. The intakes of salt, calcium, and potassium were estimated by a validated semiquantitative food frequency questionnaire (FFQ), which was developed to assess habitual dietary intake, the average intake over a one-year period (26). Since it is usually desirable in epidemiological analyses of diet-disease relationships to employ a measure of nutrient intake that is independent of total caloric intake, "energy-adjusted" intake of salt, potassium, or calcium was computed as the residual from a regression model with total caloric intake as the independent variable and absolute intake of salt, potassium, or calcium as the dependent variable (27).

Statistical analyses. All statistical analyses were performed by using SAS software, Ver. 6.12. Pearson correlation coefficients were calculated between systolic (SBP) or diastolic blood pressure (DBP) and serum vitamin $\mathrm{C}$ by sex and age groups. ANOVA (analysis of variance) was done by using the general linear model procedure (PROC GLM) to get the least-square mean of blood pressure by quartile of serum vitamin $\mathrm{C}$ and to test any difference in the distribution of blood pressure in four groups of vitamin C. Age (and sex for combined analysis) was included in the analyses to adjust for its effect on blood pressure. Pearson's correlation analyses, ANOVA and ANCOVA were also done among the subjects, excluding patients who took antihypertensive medication, a potential confounding factor between vitamin $\mathrm{C}$ and blood pressure.

Multiple linear regression analysis was performed to assess the independent relationship between serum vitamin $\mathrm{C}$ and blood pressure by sex after adjusting 
Table 1. Characteristics of 919 men and 1,266 women aged 40 years and over in the Akadani-Ijimino district, Shibata, Niigata Prefecture, Japan, 1977.

\begin{tabular}{|c|c|c|c|c|}
\hline & \multicolumn{2}{|c|}{$\begin{array}{c}\text { Men } \\
(n=919)\end{array}$} & \multicolumn{2}{|c|}{$\begin{array}{c}\text { Women } \\
(n=1,266)\end{array}$} \\
\hline & Mean & SD & Mean & $\mathrm{SD}$ \\
\hline Age (years) & 56.6 & 11.0 & 56.9 & 11.3 \\
\hline Systolic blood pressure $(\mathrm{mmHg})$ & 134.0 & 20.0 & 128.3 & 20.8 \\
\hline Diastolic blood pressure $(\mathrm{mmHg})$ & 81.0 & 11.7 & 75.8 & 11.4 \\
\hline Serum vitamin $\mathrm{C}$ concentration $(\mu \mathrm{mol} / \mathrm{L})$ & 42.5 & 18.6 & 56.8 & 16.5 \\
\hline Body mass index $\left(\mathrm{kg} / \mathrm{m}^{2}\right)$ & 22.0 & 2.6 & 22.8 & 3.3 \\
\hline Serum total cholesterol $(\mathrm{mmol} / \mathrm{L})$ & 4.36 & 1.15 & 4.84 & 1.20 \\
\hline Alcohol consumption (drinks/d) & 2.37 & 2.35 & 0.06 & 0.30 \\
\hline Smoking (cigarettes/d) & 14.5 & 12.3 & 0.5 & 2.6 \\
\hline Physical activity (index for daily activity) & 0.45 & 0.19 & 0.47 & 0.18 \\
\hline Energy intake $(\mathrm{kcal} / \mathrm{d})$ & 2,289 & 553 & 1,805 & 431 \\
\hline Salt intake $(\mathrm{g} / \mathrm{d})$ & 20.4 & 5.9 & 19.0 & 4.8 \\
\hline Calcium intake $(\mathrm{mg} / \mathrm{d})$ & 471 & 162 & 420 & 136 \\
\hline \multirow[t]{2}{*}{ Potassium intake $(\mathrm{mg} / \mathrm{d})$} & 2,672 & 605 & 2,541 & 502 \\
\hline & $\%$ & $n$ & $\%$ & $n$ \\
\hline Current smokers & 71.3 & 655 & 4.5 & 57 \\
\hline Ex-smokers & 6.0 & 55 & 0.2 & 3 \\
\hline Current alcohol drinkers & 72.9 & 670 & 9.6 & 121 \\
\hline Antihypertensive medication (self-reported) & 25.1 & 231 & 21.6 & 274 \\
\hline
\end{tabular}

for age and possible confounding variables mentioned above.

\section{RESULTS}

Of the eligible population, 919 men (response rate $78 \%$ ) and 1,266 women $(86 \%)$ who had serum vitamin $\mathrm{C}$ determination were recruited to the current analysis. The characteristics of the subjects are shown in Table 1. The means and standard deviations of SBP and DBP by sex and age are shown in Table 2. As presented in Table 3, the means of serum vitamin $\mathrm{C}$ were lower for men than for women among all age groups. In men, the means at age groups 60-69, 70-79, and 80-89 declined in comparison with those at age groups $40-49$ and 50-59. In women, the mean decreased with age, peaking at age group 50-59.

The correlation coefficients between serum vitamin $C$ concentration and SBP or DBP by sex and age are shown in Table 4. Both SBP and DBP were inversely correlated with serum vitamin $\mathrm{C}$ concentration, though some of the correlations did not reach statistical significance, especially in women. We compared serum 
Table 2. Systolic and diastolic blood pressures ( $\mathrm{mm} \mathrm{Hg}$ ) by age and sex in the A-I district, Shibata, 1977.

\begin{tabular}{|c|c|c|c|c|c|c|}
\hline \multirow{2}{*}{ Age (years) } & \multicolumn{3}{|c|}{ Men } & \multicolumn{3}{|c|}{ Women } \\
\hline & $n$ & Mean & SD & $n$ & Mean & $\mathrm{SD}$ \\
\hline \multicolumn{7}{|c|}{ Systolic blood pressure } \\
\hline $40-49$ & 301 & 130.4 & 16.4 & 396 & 122.4 & 17.7 \\
\hline $50-59$ & 268 & 130.8 & 18.4 & 376 & 124.9 & 18.6 \\
\hline $60-69$ & 225 & 138.6 & 23.1 & 286 & 130.8 & 20.5 \\
\hline $70-79$ & 100 & 140.7 & 22.1 & 171 & 139.9 & 22.0 \\
\hline $80-89$ & 25 & 143.1 & 20.2 & 37 & 153.6 & 25.9 \\
\hline All & 919 & 134.0 & 20.0 & 1,266 & 128.3 & 20.8 \\
\hline \multicolumn{7}{|c|}{ Diastolic blood pressure } \\
\hline 40-49 & 301 & 81.8 & 11.4 & 396 & 75.1 & 11.2 \\
\hline $50-59$ & 268 & 81.2 & 11.7 & 376 & 75.4 & 10.6 \\
\hline $60-69$ & 225 & 80.6 & 11.6 & 286 & 76.2 & 11.6 \\
\hline $70-79$ & 100 & 79.5 & 12.6 & 171 & 76.4 & 12.0 \\
\hline $80-89$ & 25 & 79.8 & 11.0 & 37 & 81.1 & 15.0 \\
\hline All & 919 & 81.0 & 11.7 & 1,266 & 75.8 & 11.4 \\
\hline
\end{tabular}

Table 3. Mean serum vitamin $\mathrm{C}$ concentration $(\mu \mathrm{mol} / \mathrm{L})$ by age and sex in the A-I district, Shibata, 1977.

\begin{tabular}{crrrrrrr}
\hline & \multicolumn{3}{c}{ Men } & & & \multicolumn{3}{c}{ Women } \\
\cline { 2 - 5 } \cline { 6 - 8 } Age (years) & $n$ & Mean & SD & & $n$ & Mean & SD \\
\hline $40-49$ & 301 & 44.7 & 16.8 & & 396 & 57.6 & 14.8 \\
$50-59$ & 268 & 44.9 & 17.3 & & 376 & 59.8 & 15.7 \\
$60-69$ & 225 & 40.4 & 20.0 & & 286 & 57.7 & 16.0 \\
$70-79$ & 100 & 37.1 & 21.0 & & 171 & 49.3 & 18.1 \\
$80-89$ & 25 & 28.6 & 19.5 & & 37 & 47.0 & 23.1 \\
\hline All & 919 & 42.5 & 18.6 & & 1,266 & 56.8 & 16.5 \\
\hline
\end{tabular}

concentration of vitamin $\mathrm{C}$ in the persons who took antihypertensive medication with that in the reference subjects matched for sex, age, SBP, and DBP. The mean and standard deviations of serum vitamin $C$ were $47.7 \pm 18.9 \mu \mathrm{mol} / \mathrm{L}$ in the first group and $49.3 \pm 20.1 \mu \mathrm{mol} / \mathrm{L}$ in the second. Although not statistically significant between the two groups $(p=0.15)$, antihypertensive medication might be a confounder between vitamin $\mathrm{C}$ and blood pressure. Therefore the same analysis 
N SAKAI et al

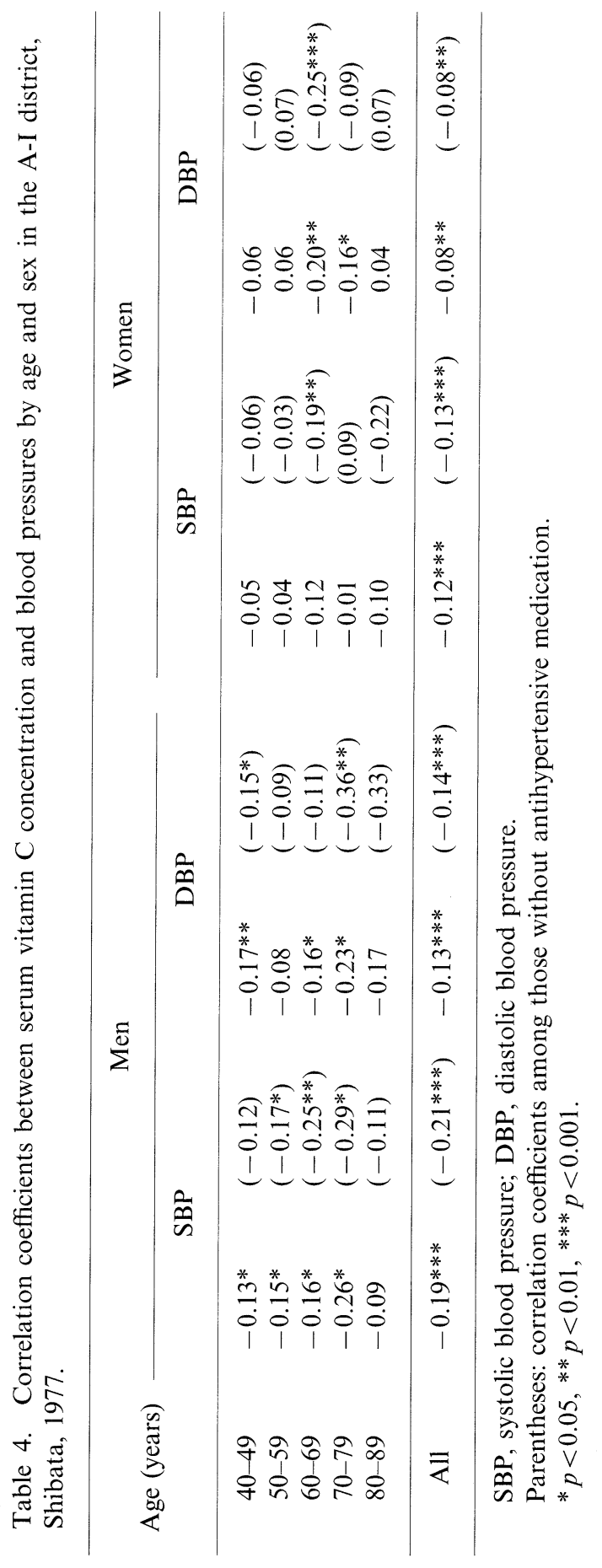




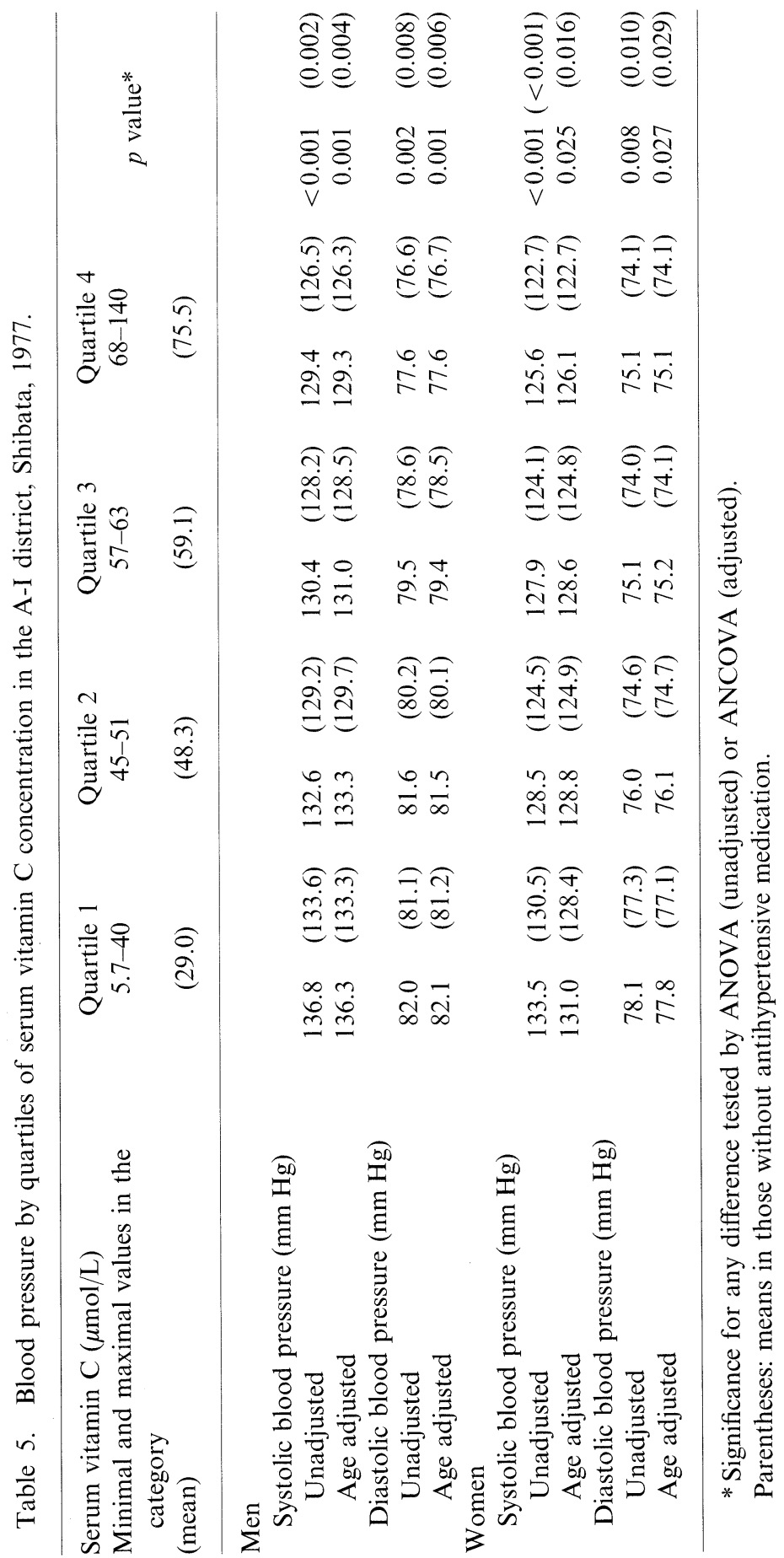


was done among the persons excluding those who had taken the medication. As shown in the parentheses of Table 4, the magnitude of the correlation coefficients did not differ markedly, whether we excluded or included those with antihypertensive medication. However, the coefficients were a little larger among those without the medication than among all subjects, especially in the older age groups.

The means of SBP and DBP are shown for quartiles of serum vitamin C level in Table 5. A consistent trend for SBP or DBP was observed over the whole range of serum vitamin $C$. This inverse trend was statistically significant, whether in men or in women, and whether adjusted or unadjusted for age. Even if the hypertensive patients with the medication were excluded from the analysis, the inverse association

Table 6. Partial correlation coefficient between serum vitamin $\mathrm{C}$ concentration and blood pressure adjusted for selected confounders.

\begin{tabular}{|c|c|c|c|}
\hline \multirow{2}{*}{ Adjusted confounders } & \multicolumn{3}{|c|}{ Partial correlation coefficient } \\
\hline & Men & Women & Both sexes \\
\hline \multicolumn{4}{|l|}{ Systolic blood pressure } \\
\hline Age & $-0.165 * * *$ & $-0.076^{* *}$ & $-0.114 * * *$ \\
\hline Age + body mass index & $-0.162 * * *$ & $-0.073 * *$ & $-0.112^{* * *}$ \\
\hline Age + serum total cholesterol & $-0.166^{* * *}$ & $-0.080 * *$ & $-0.117 * * *$ \\
\hline Age + alcohol consumption & $-0.155^{* * *}$ & $-0.075 * *$ & $-0.109 * * *$ \\
\hline Age + smoking & $-0.167 * * *$ & $-0.078 * *$ & $-0.115^{* * *}$ \\
\hline Age + physical activity & $-0.161 * * *$ & $-0.062^{*}$ & $-0.105 * * *$ \\
\hline Age + antihypertensive medication & $-0.153^{* * *}$ & $-0.070^{*}$ & $-0.105 * * *$ \\
\hline Age + daily salt intake & $-0.163^{* * *}$ & $-0.073 * *$ & $-0.112 * * *$ \\
\hline Age + daily calcium intake & $-0.148 * * *$ & $-0.073 * *$ & $-0.106^{* * *}$ \\
\hline Age + daily potassium intake & $-0.147 * * *$ & $-0.071^{*}$ & $-0.104 * * *$ \\
\hline All the above variables & $-0.121 * * *$ & $-0.060^{*}$ & $-0.084^{* * *}$ \\
\hline \multicolumn{4}{|l|}{ Diastolic blood pressure } \\
\hline Age & $-0.148 * * *$ & $-0.070 *$ & $-0.104 * * *$ \\
\hline Age + body mass index & $-0.143^{* * *}$ & $-0.067^{*}$ & $-0.101 * * *$ \\
\hline Age + serum total cholesterol & $-0.151^{* * *}$ & $-0.076 * *$ & $-0.109 * * *$ \\
\hline Age + alcohol consumption & $-0.137 * * *$ & $-0.069^{*}$ & $-0.098 * * *$ \\
\hline Age + smoking & $-0.150^{* * *}$ & $-0.071 *$ & $-0.105^{* * *}$ \\
\hline Age + physical activity & $-0.133^{* * *}$ & $-0.058 *$ & $-0.090 * * *$ \\
\hline Age + antihypertensive medication & $-0.137 * * *$ & $-0.066^{*}$ & $-0.097 * * *$ \\
\hline Age + daily salt intake $e^{\#}$ & $-0.146^{* * *}$ & $-0.069 *$ & $-0.103^{* * *}$ \\
\hline $\mathrm{Age}+$ daily calcium intake & $-0.136 * * *$ & $-0.069 *$ & $-0.099 * * *$ \\
\hline Age + daily potassium intake & $-0.132 * * *$ & $-0.068^{*}$ & $-0.096^{* * *}$ \\
\hline All the above variables & $-0.101 * *$ & $-0.058 *$ & $-0.076^{* * *}$ \\
\hline
\end{tabular}

\# Each nutrient was adjusted for total energy intake by the residual method.

${ }^{*} p<0.05,{ }^{* *} p<0.01,{ }^{* * *} p<0.001$. 
of serum vitamin $\mathrm{C}$ with blood pressure was detected, though the means of SBP and DBP by quartile were lower for those without the medication than for those including it, as seen in the parentheses of Table 5 .

The partial correlation coefficients between serum vitamin C and SBP or DBP are shown in Table 6 . The adjustment was done for age plus each of 9 confounding variables and for all 10 variables. The inverse relationship between serum vitamin $\mathrm{C}$ and SBP or DBP remained statistically significant after any adjustment. This association was stronger in men than in women.

\section{DISCUSSION}

We used only one measurement of nonfasting serum vitamin $\mathrm{C}$ and two or more blood pressure readings on one occasion to characterize the status of an individual. It is important to examine if the values obtained are representative of a subject's usual levels. Our use of serum vitamin $\mathrm{C}$ was principally as a measure of dietary intake of vitamin C. Unfortunately, the degree to which the level of serum vitamin $\mathrm{C}$ could reflect true dietary intake over a long period was not examined in this study. Jacob reported that leukocyte vitamin $\mathrm{C}$ was probably a preferable measure of long-term intake, whereas serum level reflected a more recent intake (28). Although a single serum vitamin $\mathrm{C}$ determination would misclassify many individuals with respect to their actual long-term intake, serum was probably more appropriate for the present study with the large sample size because more expertise, expense, and time were needed to separate and store leukocytes. In 1981 we had an opportunity to remeasure serum vitamin $C$ and blood pressure for 862 persons of 2,185 subjects who received the baseline examination in 1977. The age-adjusted correlation coefficient between two measurements of serum vitamin $\mathrm{C}$ was 0.53 for men and 0.43 for women, which was higher than that between plasma vitamin $C$ values in men obtained 6 years apart in another study $(r=0.28)$ (27). On the other hand, the correlation between our two measurements in 1977 and 1981 was 0.64 for SBP and 0.59 for DBP. Among 863 men and women measured at an interval of 4 years, Rosner and colleagues found correlations of 0.64 for SBP and 0.60 for DBP (29), which were comparable with ours. Although a high degree of reproducibility does not always ensure validity, the correlations on the order of 0.5 to 0.6 among free-living subjects over a period of years indicated that only one measurement of blood pressure or serum vitamin $C$ would provide a fairly good measure of long-term level (27).

Since the temporal sequence of cause and effect cannot necessarily be determined in cross-sectional studies, it is impossible to ensure that any observed association is the cause rather than the result of the disease. Elevated blood pressure or antihypertensive medication would possibly lead to a decreased level of serum vitamin C. After the exclusion of known hypertensives and adjustments of sex, age, and other confounders, the inverse relationship between vitamin $\mathrm{C}$ and blood pressure persisted in the present study (partial correlation coefficient $=-0,099$, 
$p<0.001$, for SBP and $-0.087, p<0.001$, for DBP). The same analysis was done after excluding the patients who took antihypertensive medication. The partial correlation was $-0.135(p<0.001)$ for SBP, and $-0.118(p<0.001)$ for DBP. These results suggested the possibility of cause-effect reversal was low, although prospective and intervention studies would be required to establish the causal relationship.

As shown in Tables 4 and 6, the absolute values of simple or partial correlation coefficients were relatively small, around -0.1 , but consistent with other cross-sectional studies $(1,6,9-11)$. In a study of diet and disease, failure to observe a strong association can occur when such an association truly exists. Several biological and methodological reasons were addressed for failure to observe an association (27). Among them, two circumstances could obscure the relationship in the present study. One possibility was that the variation in the level of serum vitamin $\mathrm{C}$ might exist within a flat portion of the dose-response relationship [According to the hypothetical relationship between a nutritional factor and health, the dose-response curve was divided into three parts: ascending, horizontal, and descending segments (27)], because apparently healthy persons were the subjects, and those with serious deficiency or toxicity of vitamin $\mathrm{C}$ were not observed. Second, mentioned earlier, a single determination of blood pressure or vitamin $\mathrm{C}$ would not be substantially and sufficiently precise to detect interindividual differences in the long-term level that truly exist. The random measurement error due to interindividual variability is likely to obscure relationships rather than to produce spurious ones (11). Thus the association was not likely to be strong. However, the weak association could potentially be important because the dietary exposure was common. On the basis of Table 5, for example, when the intake of vegetables and fruits increases and, as a result, the level of serum vitamin $\mathrm{C}$ increases to 75.5 $\mu \mathrm{mol} / \mathrm{L}$ (mean for Quartile 4), from $29.0 \mu \mathrm{mol} / \mathrm{L}$ (mean for Quartile 1), SBP would decrease by $7 \mathrm{mmHg}(=136.3-129.3)$ on average.

Ness and colleagues searched MEDLINE (1966-1996) and EMBASE (19801996) and reviewed epidemiological studies of vitamin $C$ and blood pressure (20). We also searched MEDLINE for 1966-1998, but found no other report on vitamin $\mathrm{C}$ status and blood pressure. According to the review article (20) and our confirmation of the original papers, 11 cross-sectional studies analyzed the association between plasma or serum levels of vitamin $C$ and blood pressure in 14 populations $(1-11)$. Ten of the 14 populations reported the significant inverse relationship $(1-4,6-11)$, though the sample size was usually small and adjustment for other confounding variables was not adequate. None of the studies adjusted for confounding by other dietary factors. Among 11 studies, however, a report by Ness et al had the largest number of subjects; 1,860 volunteers, and it observed the inverse relationship after taking into account several confounders except for dietary variables (11). The present study was characterized in the large sample size ( 2,185 subjects), community-based population as the subjects, high response rate, and adjustment for possible confounders, including dietary factors. 
Five studies cross-sectionally analyzed the association between dietary intake of vitamin $\mathrm{C}$ and $\mathrm{BP}$ in 4 populations (12-16). Four were based on a single 24-h recall (12-15) and the rest on 3-d dietary record (16) to assess habitual intake. Although the associations observed in the studies by these short-term dietary methods tended to underestimate the true association, three found out the significant inverse relationship $(12,15,16)$.

A high intake of fruits and vegetables appeared to be consistently and inversely related to blood pressure (30), though these foods contain not only vitamin C, but also potassium, calcium, and fiber, and it was unclear which one(s) was responsible for lowering blood pressure.

The Western Electric Study was the only one cohort study on the relationship of vitamin C status to hypertension in which a 10-year increase in SBP was estimated to be less by $2 \mathrm{mmHg}$ for the persons with $125 \mathrm{mg} / \mathrm{d}$ of vitamin $\mathrm{C}$ than for those with $75 \mathrm{mg} / \mathrm{d}$ (17). However, more detailed information was not available because this was not a full paper, but an abstract of a scientific meeting.

Several uncontrolled and controlled trials of vitamin $\mathrm{C}$ alone and multivitamin supplementation were reported. Two uncontrolled studies of vitamin C supplementation alone showed the inverse association $(31,32)$. Among four controlled studies, two showed a significant reduction in SBP but not in DBP $(33,34)$, and the others showed nonsignificant reduction in both SBP and DBP $(35,36)$. One multivitamin supplementation study found no effect on blood pressure (37), but the other found a statistically significant reduction in SBP after a 6-year follow-up on more than 3,000 Chinese with oesophageal dysphasia (38).

The findings from epidemiological studies generally supported the hypothesis that vitamin $\mathrm{C}$ might reduce the risk of coronary heart disease and stroke, though they were not totally consistent $(18,19)$. Although, as described later, the decreased risk observed may be caused by vitamin $\mathrm{C}$ itself, it may be due to some other characteristics of the individuals. It is well known that smoking is inversely associated with vitamin C status (39). Furthermore, Ness et al reported that plasma vitamin $\mathrm{C}$ was positively correlated with high-density lipoprotein (HDL) cholesterol and negatively correlated with triglyceride, but it was not correlated with total cholesterol or low-density lipoprotein (LDL) cholesterol (40). In our present study, the age-adjusted correlation coefficient between serum vitamin $\mathrm{C}$ and total cholesterol was 0.04 (not significant) for men and 0.07 (not significant) for women. These findings suggested that vitamin $\mathrm{C}$ might favorably influence traditional cardiovascular risk factors, i.e., blood pressure, blood lipids (HDL-cholesterol and triglyceride), and smoking, and the relationship of vitamin $\mathrm{C}$ to coronary heart disease and stroke might be mediated through the risk factors.

Although the U.S. Joint National Committee on Prevention, Detection, Evaluation, and Treatment of High Blood Pressure (JNC VI) reported that no convincing data currently justified recommending an increased magnesium intake in an effort to lower blood pressure (41), evidence suggested an association between lower dietary magnesium intake and higher blood pressure (42). We 
should have taken into account the potential effect of dietary magnesium on the inverse relationship between vitamin $\mathrm{C}$ and blood pressure. Unfortunately, however, information about magnesium intake was not available.

Several biological mechanisms have been proposed to explain the inverse association of serum vitamin $\mathrm{C}$ concentrations with blood pressure. All are based on the "oxidative-modification hypothesis," which proposes that atherogenesis is initiated by oxidation of the lipids in LDL (43). According to Retsky et al, vitamin $C$ protected LDL against oxidation but was not incorporated into LDL because it is water-soluble (44), though lipid-soluble antioxidants accumulated within the LDL particle and increased the resistance of LDL to oxidative modification.

Oxidized LDL is toxic to vascular cells. Antioxidants may lower the cytotoxicity of the oxidized LDL toward endothelial cells. Oxidized LDL impaired the release of nitric oxide from normal arteries (45), through which, in part, the vascular endothelium prevented inappropriate adhesion of leukocytes and platelets and vasospasm. Besides improving nitric oxide action by reducing the oxidation of LDL, antioxidants are beneficial to vascular function through other mechanisms (43). Endothelium-derived nitric oxide-mediated vascular relaxation was reduced in cholesterol-fed rabbits, but this reduction was prevented by the administration of $\alpha$-tocopherol, $\beta$-carotene, or probucol $(43,46)$. As for vitamin $\mathrm{C}$, however, since it is said that vitamin $\mathrm{C}$ is concentrated within cells and resists the cytotoxicity of oxidized LDL, one must consider other mechanisms, such as the scavenging of superoxide or an improvement in intracellular antioxidant status (43).

The administration of an antioxidant reduced the sensitivity of platelets to activation by platelet agonists and inhibited smooth-muscle proliferation (47).

Thus cellular antioxidants inhibit monocyte adhesion, protect against the cytotoxic effects of oxidized LDL, inhibit platelet activation, and protect against the endothelial dysfunction associated with atherosclerosis by preserving endothelium-derived nitric oxide activity (43), though each antioxidant vitamin does not always work in the same way.

In conclusion, the serum concentration of vitamin $\mathrm{C}$ appeared to be independently and inversely related to both SBP and DBP in this Japanese population, though the strength of association was weak. Thus we were able to form the hypothesis that vitamin $\mathrm{C}$ would reduce the level of blood pressure. Further intervention studies (or cohort studies, though difficult to conduct) will be required to test the hypothesis. Experimental studies will also be encouraged to show the biological plausibility on the molecular or DNA levels.

Appreciation is extended to the following persons: Drs. Heizo Tanaka, Terumi Baba, Masayuki Hayashi, and to our other colleagues, and to many collaborators in Shibata City.

\section{REFERENCES}

1) Koh ET, Stewart T. 1978. Interrelationship among the blood components and 
anthropometric measurements. Nutr Rep Int 18: 539-549.

2) Koh ET, Chi MS. 1980. Relationship of serum vitamin C and globulin fractions with anthropometric measurements in adults. Nutr Rep Int 21: 537-549.

3) Yoshioka M, Matsushita T, Chuman Y. 1984. Inverse association of serum scorbic acid level and blood pressure or rate of hypertension in male adults aged 30-39 years. Int J Vit Nutr Res 54: 343-347.

4) Salonen JT, Salonen R, Ihanainen M, Parviainen M, Seppanen R, Kantola M, Seppanen K, Rauramaa R. 1988. Blood pressure, dietary fats, and antioxidants. Am J Clin Nutr 48: $1226-1232$.

5) Riemersma RA, Oliver M, Elton RA, Alfthan G, Vartianinen E, Salo M, Rubba P, Mancini M, Georgi H, Vuilleumier JP. 1990. Plasma antioxidants and coronary heart disease: Vitamin C and E, and selenium. Eur J Clin Nutr 44: 143-150.

6) Choi ESK, Jacques PF, Dallal GE, Jacob RA. 1991. Correlation of blood pressure with plasma ascorbic acid. Nutr Res 11: 1377-1382.

7) Jacques PF. 1992. A cross-sectional study of vitamin C intake and blood pressure. $J$ Am Coll Nutr 11: 139-144.

8) Moor de Burgos A, Wartanowicz M, Ziemlanski S. 1992. Blood vitamin and lipid levels in overweight and obese women. Eur J Clin Nutr 46: 803-808.

9) Toohey L, Harris MA, Allen KG, Melby CL. 1996. Plasma ascorbic acid concentrations are related to cardiovascular risk factors in African-Americans. $J$ Nutr 126: 121-128.

10) Moran JP, Cohen L, Greene JM, Xu G, Feldman EB, Hames CG, Feldman DS. 1993. Plasma ascorbic acid concentrations relate inversely to blood pressure in human subjects. Am J Clin Nutr 57: 213-217.

11) Ness AR, Khaw K, Bingham S, Day NE. 1996. Vitamin C status and blood pressure. J Hypertens 14: 503-508.

12) Stanton JL, Braitman LE, Riley AM Jr, Khoo CS, Smith JL. 1982. Demographic, dietary and life style, and anthropometric correlates of blood pressure. Hypertension 4: III135-III142.

13) Harlan WR, Hull AL, Schmouder RL, Landis JR, Thompson FE, Larkin FA. 1984. Blood pressure and nutrition in adults: The national health and nutrition examination survey. Am J Epidemiol 120: 17-28.

14) Lapidus L, Andersson H, Bengtsson C, Bosaeus I. 1986. Dietary habits in relation to incidence of cardiovascular disease and death in women: a 12-year follow-up of participants in the population study of women in Gothenburg, Sweden. Am J Clin Nutr 44: 444-448.

15) Joffres MR, Reed DM, Yano K. 1987. Relationship of magnesium intake and other dietary factors to blood pressure: the Honolulu heart study. Am J Clin Nutr 45: 469-475.

16) Jacques PR. 1992. A cross-sectional study of vitamin C intake and blood pressure in the elderly. Int $J$ Vit Nutr Res 62: 252-255.

17) Stamler J, Ruth KJ, Liu K, Shekelle RB. 1994. Dietary antioxidants and blood pressure change in the Western electric study, 1958-66. Circulation 89: 932.

18) Daviglus ML, Orencia AJ, Dyer AR, Liu K, Morris DK, Persky V, Chavez V, Goldberg J, Drum M, Shekelle RB, Stamler J. 1997. Dietary vitamin C, beta-carotene and 30-year risk of stroke: results from the Western electric study. Neuroepidemiology 16: 69-77.

19) Gey KF, Stahelin HB, Eichholzer M. 1993. Poor plasma status of carotene and vitamin $\mathrm{C}$ is associated with higher mortality from ischaemic heart disease and stroke. Basel prospective study. Clin Invest 71: 3-6.

20) Ness AR, Chee D, Elliott P. 1997. Vitamin C and blood pressure-an overview. $J$. Hum Hypertens 11: 343-350.

Vol 44, No 6, 1998 
21) Tanaka H, Hayashi M, Date C, Imai K, Asada M, Shoji H, Okazaki K, Yamamoto H, Yoshikawa K, Shimada T, Lee SI. 1985. Epidemiologic studies of stroke in Shibata, a Japanese provincial city: A preliminary report on risk factors for cerebral infarction. Stroke 16: 773-780.

22) Rose GA, Blackburn H, Gillum RF, Prineas RJ. 1982. Cardiovascular Survey Methods, second ed, p 82-85. WHO, Geneva.

23) Lowry OH, Lopez JA, Bessey OA. 1945. The determination of ascorbic acid in small amounts of blood serum. J Biol Chem 160: 609-615.

24) Baba T, Tanaka H, Date C, Ueda Y, Hayashi M, Owada K. 1976. Supplemental study on the determination of serum ascorbic acid for a large number of samples. $J$ Osaka City Med Center 25: 273-285.

25) Baba T, Tanaka H, Date C, Ueda Y, Hayashi M, Yamashita H, Shoji H, Yoshikawa K, Okazaki K, Owada K. 1980. The outline and validity of a simplified energy expenditure estimation. Jpn J Public Health 27: 259-266.

26) Date C, Yamaguchi M, Tanaka H. 1996. Development of a food frequency questionnaire in Japan. J Epidemiol 6 (Suppl): S131-S136.

27) Willett W. 1990. Nutritional Epidemiology. p 261-265, 170-172, 96-97. Oxford University Press, New York, Oxford.

28) Jacob RA, Skala JH, Omaye SJ. 1987. Biochemical indices of human vitamin C status. Am J Clin Nutr 46: 818-826.

29) Rosner B, Hennkens CH, Kass EH, Miall WE. 1977. Age-specific correlation analysis of longitudinal blood pressure data. Am J Epidemiol 106: 306-313.

30) Beilin LJ. 1994. Vegetarian and other complex diets, fats, fiber, and hypertension. Am $J$ Clin Nutr 59: 1130S-1135S.

31) Koh ET. 1984. Effect of vitamin C on blood parameters of hypertensive subjects. $J$ Oklahoma Med Assoc 77: 177-182.

32) Feldman EB, Gold S, Greene J, Moran J, Xu G, Shultz GG, Hames CG, Feldman DS. 1992. Ascorbic acid supplements and blood pressure: A four-week pilot study. Ann NY Acad Sci 669: 342-344.

33) Mostafa SE, Garner DD, Garrett L, Whaley RF, ee-Sekate M, Kiker M. 1989. Beneficial effects of vitamin $\mathrm{C}$ on risk factors of cardiovascular disease. $J$ Egypt Public Health Assoc 64: 123-133.

34) Osilesi O, Trout DL, Ogunwole JO, Glover EE. 1991. Blood pressure and plasma lipids during ascorbic acid supplementation in borderline hypertensive and normotensive adults. Nutr Res 11: 405-412.

35) Lovat LB, Lu Y, Palmer AJ, Edwards R, Fletcher AE, Bulpitt CJ. 1993. Double-blind trial of vitamin C in elderly hypertensives. J Hum Hypertens 7: 403-405.

36) Ghosh SK, Ekpo EB, Shah IU, Girling AJ, Genkins C, Sinclair AJ. 1994. A double-blind placebo-controlled parallel trial of vitamin $\mathrm{C}$ treatment in elderly patients with hypertension. Gerontology 40: 268-272.

37) Salone JT. 1991. Dietary fats, antioxidants and blood pressure. Ann Med 23: 295298.

38) Mark SD, Wang W, Fraumeni JF Jr, Li JY, Taylor PR, Wang GQ, Guo W, Dawsey SM, Li B, Blot WJ. 1996. Lowered risks of hypertension and cerebrovascular disease after vitamin/mineral supplementation. Am J Epidemiol 43: 658-664.

39) Dickinson VA, Block G, Russek-Cohen E. 1994. Supplement use, other dietary and demographic variables, and serum vitamin C in NHANES II. $J$ Am Coll Nutr 13: $22-32$.

40) Ness AR, Khaw KT, Bingham S, Day NE. 1996. Vitamin C status and serum lipids. 
Eur J Clin Nutr 50: 724-729.

41) The Joint National Committee on Prevention, Detection, Evaluation and Treatment of High Blood Pressure and the National High Blood Pressure Education Program Coordinating Committee. 1997. The Sixth Report of the Joint National Committee on Prevention, Detection, Evaluation, and Treatment of High Blood Pressure. Arch Intern Med 157: 2413-2446.

42) Stamler J, Caggiula AW, Grandits GA. 1997. Chapter 12, Relation of body mass and alcohol, nutrient, fiber, and caffeine intakes to blood pressure in the special intervention and usual care groups in the multiple risk factor intervention trial. Am J Clin Nutr $\mathbf{6 5}$ (suppl): 338S-365S.

43) Diaz MN, Frei B, Vita JA, Keaney JF. 1997. Antioxidants and atherosclerotic heart disease. New Engl J Med 337: 408-416.

44) Retsky KL, Freeman MW, Frei B. 1993. Ascorbic acid oxidation product(s) protect human low density lipoprotein against atherogenic modification: anti-rather than prooxidant activity of vitamin $\mathrm{C}$ in the presence of transition metal ions. $J$ Biol Chem 268: 1304-1309.

45) Chin JH, Azhar S, Hoffman BB. 1992. Inactivation of endothelial derived relaxing factor by oxidized lipoproteins. $J$ Clin Invest 89: 10-18.

46) Steward-Lee AL, Forster LA, Nourooz-Zadeh J, Ferns GAA, Anggard EE. 1994 Vitamin $\mathrm{E}$ protects against impairment of endothelium-mediated relaxations in cholesterol-fed rabbits. Arterioscler Thromb 14: 494 499.

47) Freedman JE, Farhat JH, Loscalzo J, Keaney JF Jr. 1996. $\alpha$-Tocopherol inhabits aggregation of human platelets by a protein kinase $\mathrm{C}$-dependent mechanism. Circulation 94: $2434-2440$. 